Consultant for: AbbVie, Actelion, Amgen, BMS, GSK, Lilly, Merck, Novartis, Pfizer, Roche, Sandoz, Sanofi, UCB

DOI: 10.1136/annrheumdis-2018-eular.2862

\section{AB0732 EFFICACY AND SAFETY OF RITUXIMAB IN SYSTEMIC SCLEROSIS: FRENCH RETROSPECTIVE STUDY AND LITERATURE REVIEW}

M. Thiébaut ${ }^{1}$, D. Launay ${ }^{2}$, S. Rivière ${ }^{1}$, T. Mahévas $^{1}$, S. Bellakhal ${ }^{3}$, E. Hachulla ${ }^{2}$, O. Fain ${ }^{1}$, A. Mekinian ${ }^{1} .^{1}$ Médecine Interne, Hôpital Saint-Antoine AP-HP, Paris; ${ }^{2}$ Médecine Interne, Hôpital Claude Huriez CHU Lille, Lille, France; ${ }^{3}$ Médecine Interne, Hôpital des Forces de Sécurité Intérieure, La Marsa, Tunisia

Background: Interstitial lung disease occurs in $42 \%$ of diffuse SSc patients and have a major impact on the overall survival. ${ }^{1}$ Cyclophosphamide and mycophenolate mofetil can allow the lung disease stabilisation., ${ }^{2,3}$ Recently several casereports and little series reported the efficacy of rituximab in SSc, showing a possible improvement of pulmonary involvements. ${ }^{4,5,6}$ Large studies are lacking to determine the factors associated with rituximab response, the maintenance regimen and the long term efficacy of rituximab in SSc.

Objectives: To describe safety and efficacy of rituximab in patients with systemic sclerosis.

Methods: We included 13 patients with systemic sclerosis treated with rituximab and pooled with 40 additional patients from the literature. SSc rituximab untreated patients were matched to rituximab treated ones.

Results: Thirteen patients who received rituximab and 26 rituximab-untreated patients were included. In comparison to 26 patients who did not received rituximab, FVC changes were not significantly different, whereas DLCO improved in 13 patients who received rituximab $(0[-4 ; 4]$ vs loss of -7 [ $-19 ; 0]$; $p=0.05)$. Considering 7 rituximab treated and 14 untreated diffuse SSc, FVC was improved during the $24^{12 ;} 46$ months of follow up in dSSc who received rituximab (gain of 12 $[7.5: 14] \%$ vs loss of $1.5[-16.8 ; 2.5],(\mathrm{p}=0.003)$. Pooled analysis of 53 patients $(40$ literature patients and 13 from personal series) showed significant improvement of median mRSS from $18^{8 ; 32}$ at baseline to $9^{4 ; 18}$ at M6 $(p=0.007), 13^{8 ; 18}$ at M12 $(p=0.008)$ and $10^{4 ; 16}$ at the last follow-up $(p=0.0002)$. FVC increased from $71 \%{ }^{66}$; 80 at baseline to $84 \%{ }^{75 ;} ; 0$ at M12 ( $\left.p=0.001\right)$. DLCO increased from $58 \%{ }^{39 ; 65}$ at $\mathrm{M} 0 \%$ to $63 \%{ }^{53 ; 78}$ at $\mathrm{M} 12(\mathrm{p}=0.04)$.

Conclusions: Our personal data and pooled literature analysis suggest the efficacy of rituximab in the subset of diffuse SSc in particular in skin and interstitial disease involvements. The safety of rituximab seems to be reasonable and similar to previous data in other autoimmune diseases.

\section{REFERENCES}

[1] Nihtyanova SI, Schreiber BE, Ong VH, et al. Prediction of pulmonary complications and long-term survival in systemic sclerosis. Arthritis Rheumatol Hoboken NJ 2014;66:1625-35.

[2] Tashkin DP, Elashoff R, Clements PJ, et al. Cyclophosphamide in scleroderma lung disease. N Engl J Med 2006;355:1173-1174.

[3] Tashkin DP, Roth MD, Clements PJ, et al. Mycophenolate mofetil versus oral cyclophosphamide in scleroderma-related interstitial lung disease (SLS II): a randomised controlled, double-blind, parallel group trial. Lancet Respir Med 2016:4:708-19.

[4] Lafyatis R, Kissin E, York M, et al. B cell depletion with rituximab in patients with diffuse cutaneous systemic sclerosis. Arthritis Rheum 2009;60:578-83.

[] 5)

Bosello S, De Santis M, Lama G et al. B cell depletion in diffuse progressive systemic sclerosis: safety, skin score modification and IL-6 modulation in an up to thirty-six months follow-up open-label trial. Arthritis Res Ther 2010;12:1

[6] Daoussis D, Liossis S-NC, Tsamandas AC, et al. Experience with rituximab in scleroderma: results from a 1-year, proof-of-principle study. Rheumatology 2010;49:271-80.

Disclosure of Interest: None declared

DOI: 10.1136/annrheumdis-2018-eular.4101

\section{$\mathrm{AB} 0733$}

ASSOCIATION OF HAEMATOLOGICAL PARAMETERS WITH DISEASE MANIFESTATIONS, ACTIVITY, AND SEVERITY IN PATIENTS WITH SYSTEMIC SCLEROSIS

M.E. Yayla ${ }^{1}$, U. İlgen ${ }^{2}$, I.E. Okatann ${ }^{1}$, E. Uslu Yurteri ${ }^{1}$, M. Torğutalp ${ }^{1}$, A.B. Keleşoğlu Dinçer ${ }^{1}$, E.G. Aydemir Gülöksüz ${ }^{1}$, S. Sezer ${ }^{1}$, T.M. Turgay ${ }^{1}$, G. Kınıkı ${ }^{1}$, A. Ates ${ }^{1}$.

${ }^{1}$ Department of Rheumatology, Ankara University Faculty of Medicine, Ankara; ${ }^{2}$ Department of Rheumatology, Trakya University Faculty of Medicine, Edirne, Turkey

Background: Neutrophil-to-lymphocyte ratio (NLR), monocyte-to-lymphocyte ratio (MLR), eosinophil-to-lymphocyte ratio (ELR), basophil-to-lymphocyte ratio $(B L R)$, and mean platelet volume (MPV) may potentially reflect inflammatory status in systemic autoimmune diseases.

Objectives: The aim of this study is to investigate the association of NLR, MLR, ELR, BLR and MPV with disease manifestations, activity and severity in patients with systemic sclerosis (SSc).

Methods: 59 patients with SSc and 50 healthy controls were included in the study. All patients were diagnosed according to the 2013 ACR/EULAR systemic sclerosis classification criteria. Adult patients with SSc and healthy controls were compared in terms of NLR, MLR, ELR, BLR and MPV.

Results: SSc and control groups had similar ages and genders. Lymphocyte number was lower in SSc group compared to controls $(p<0.001)$. SSc group also have higher NLR and MLR (table 1). There were no significant differences in ELR and BLR ratios between SSc patients and controls. Patients with active disease (2.9 [IQR 2.13], $\mathrm{p}=0.042$ ), pulmonary hypertension (PHT), digital ulcers, and tendon friction rubs (TFR) had higher NLRs (table 2). MLR was also higher in dcSSc patients $(0.28$ [IQR 0.73$]$ ) compared to IcSSc $(0.2$ [IQR 0.48] ( $\mathrm{p}=0.045)$, and there were also significant associations with disease manifestations like digital ulcers, tendon friction rubs (table 2 ). MLR was positively correlated with $\mathrm{mRSS}$ (rho $=0.35$ $\mathrm{p}=0.009$ ), Valentini ( $\mathrm{rho}=0.453 \mathrm{p}=0.001$ ) and Medsger ( $\mathrm{rho}=0.283 \mathrm{p}=0.036$ ) scores. According to capillaroscopy images, patients with late stage findings had higher MLRs compared to patients with normal findings ( 0.27 [IQR 0.3 ] vs 0.15 [IQR 0.04], $p<0.001)$. Patients with digital ulcers $(p=0.02)$ and arthritis $(p=0.013$ had higher ELRs and patients with tendon friction rubs has higher ELRs $(p=0.014)$ and BLRs (0.036) compared to those without. There was no significant relation between MPV and disease manifestations (table 2). There were no relationships between dysmotility and haematological parameters.

Abstract AB0733 - Table 1. Comparison of laboratory features of disease and control groups

\begin{tabular}{lccc}
\hline & SSc $\mathbf{n = 5 9}$ & Control $\mathbf{n = 5 0}$ & p value \\
\hline Neutrophil $^{\star}$ & $4.13(11.88)$ & $3.57(5.19)$ & 0.150 \\
Lymphocyte $^{\star}$ & $1.67(3.04)$ & $2.08(2.75)$ & $<0.001$ \\
Monocyte $^{\star}$ & $0.34(1.21)$ & $0.35(0.73)$ & 0.959 \\
CRP, mg/L & $2.3(29.9)$ & $1.2(8.1)$ & $\mathbf{0 . 0 3 1}$ \\
ESR, mm/hour & $19(58)$ & $13(30)$ & 0.092 \\
MPV, fl & $9(4.8)$ & $8.7(5.3)$ & 0.557 \\
NLR & $2.47(7.82)$ & $1.73(2.29)$ & $<\mathbf{0 . 0 0 1}$ \\
MLR & $0.20(0.79)$ & $0.16(0.34)$ & $<\mathbf{0 . 0 0 1}$ \\
\hline
\end{tabular}

${ }^{*} \times 10^{9} / \mathrm{L}(\mathrm{IQR})$

Abstract AB0733 - Table 2. Association of disease manifestations with NLR, MLR and MPV

\begin{tabular}{lcccc}
\hline & $\mathbf{n}=59^{*}$ & MPV & NLR & MLR \\
\hline ILD & $+(n=17)$ & $8.9(2.8)$ & $2.71(7.82)$ & $0.21(0.77)$ \\
& $-(n=42)$ & $9(4.8)$ & $2.43(3.92)$ & $0.2(0.32)$ \\
PHT & $P$ & 0.412 & 0.431 & 0.738 \\
& $+(n=3)$ & $9.2(1.3)$ & $3.2(1.78)$ & $0.26(0.11)$ \\
Digital UIcer & $-(n=56)$ & $9(4.8)$ & $2.43(7.82)$ & $0.2(0.82)$ \\
& $P$ & 0.856 & 0.044 & 0.276 \\
& $+(n=12)$ & $9.1(3.4)$ & $2.75(3.05)$ & $0.27(0.74)$ \\
TFR & $-(n=47)$ & $8.9(4.8)$ & $2.43(4.31)$ & $0.19(0.48)$ \\
& $P$ & 0.971 & 0.049 & 0.009 \\
& $+(n=5)$ & $9.1(1.6)$ & $3.62(1.26)$ & $0.28(0.27)$ \\
& $-(n=54) p$ & $9(4.8)$ & $2.41(4.31)$ & $0.2(0.48)$ \\
& & 0.911 & 0.003 & $\mathbf{0 . 0 3 0}$ \\
\hline
\end{tabular}

MPV, NLR and MLR are given as medians (interquartile ranges).+and - denote presence and absence, respectively.

Conclusions: According to our study, as NLR and MLR are simple, practical, cost-effective markers, they can used for evaluation of disease manifestations, activity and severity in SSc.

Disclosure of Interest: None declared

DOI: 10.1136/annrheumdis-2018-eular.2667 